\title{
The quantitative estimation of the vulnerability of brick and concrete wall impacted by an experimental boulder
}

\author{
J. Zhang ${ }^{1,2}$, Z. X. Guo ${ }^{2}$, D. Wang ${ }^{2,3}$, and H. Qian ${ }^{4}$ \\ ${ }^{1}$ School of Energy and Power Engineering, Key Laboratory of Fluid and Power Machinery, Ministry of Education, \\ Xihua University, Chengdu, 610039, China \\ ${ }^{2}$ State Key Laboratory of Hydraulics and Mountain River Engineering, Sichuan University, Chengdu, 610065, China \\ ${ }^{3}$ Highway Planning Survey \& Design Institute, Sichuan Communications Department, Chengdu, 610041, China \\ ${ }^{4}$ Chengdu Municipal Engineering Design and Research Institute, Chengdu, 610015, China
}

Correspondence to: Z.X. Guo (scugzx@scu.edu.cn)

Received: 18 July 2015 - Published in Nat. Hazards Earth Syst. Sci. Discuss.: 26 August 2015

Revised: 21 December 2015 - Accepted: 26 December 2015 - Published: 3 February 2016

\begin{abstract}
There is little historic data about the vulnerability of damaged elements due to debris flow events in China. Therefore, it is difficult to quantitatively estimate the vulnerable elements suffered by debris flows. This paper is devoted to the research of the vulnerability of brick and concrete walls impacted by debris flows. An experimental boulder (an iron sphere) was applied to be the substitute of debris flow since it can produce similar shape impulse load on elements as debris flow. Several walls made of brick and concrete were constructed in prototype dimensions to physically simulate the damaged structures in debris flows. The maximum impact force was measured, and the damage conditions of the elements (including cracks and displacements) were collected, described and compared. The failure criterion of brick and concrete wall was proposed with reference to the structure characteristics as well as the damage pattern caused by debris flows. The quantitative estimation of the vulnerability of brick and concrete wall was finally established based on fuzzy mathematics and the proposed failure criterion. Momentum, maximum impact force and maximum impact bending moment were compared to be the best candidate for disaster intensity index. The results show that the maximum impact bending moment seems to be most suitable for the disaster intensity index in establishing vulnerability curve and formula.
\end{abstract}

\section{Introduction}

After Wenchuan Earthquake on 12 May 2008, several catastrophic earthquake events in high magnitude $(>6.5)$ occurred in China recently. For example, Yushu earthquake in Qinghan on 14 April 2010; Lushan earthquake in Ya'an, Sichuan on 20 April 2013; Ludian earthquake in Zhaotong, Yunnan on 3 August 2014 (Earthquake in China, http://www. ceic.ac.cn/). Huge volumes of sediment deposits and debris sources have been induced by earthquakes and contributed to new debris flow in higher frequency magnitude leading to much loss, both in life and economics (Tang et al., 2011b). Risk management is popularly applied to relieve or prevent debris flow disaster. Quantitative vulnerability estimation is a necessary element of risk estimation. During decades, however, the vulnerability research of debris flow had a slow development for several reasons. First, it is widely accepted that the behavior of debris flow is quite complicated and has not been clearly revealed yet (Rickenmann, 1999; Cui, 2009). Second, there are many kinds of vulnerable elements potentially affected by debris flow, and the indicator system involves many influence factors not only in natural vulnerability but also in social vulnerability (for example, economics, environment and human life) (Liu et al., 2012). Third, historic data are of much use for estimating vulnerability with a statistical approach, or for improving the accuracy of results (Totsching et al., 2011; Jakcob et al., 2012). Unfortunately, most of the databases and reports are about characteristics of debris flows but not on the vulnerability of the ele- 
ments at risk (Tang et al., 2011a; Zhang et al., 2013). Fourth, the lack of data in vulnerability research is also relevant to the little attention from both engineers and scientists in past years. Unlike earthquakes and cyclones, local structural protection measures are quite applicable to decrease the damages caused by debris flows (Douglas, 2007).

There are mainly four evaluation methods for the vulnerability of the elements in debris flow: multi-index assessment, element value accounting, empirical vulnerability curve and physical experiment. Among these, the first two methods were widely applied in China for the regional vulnerability estimation based on the category and market value of affected elements. These methods are applicable for the regions that have a vast territory or high density of vulnerable elements. However, they fail to connect with debris flow intensity (Liu et al., 2001; Tang et al., 2005; Tie, 2009). Empirical vulnerability curves are applied mainly by European researchers. The curves are fitted with empirical data including the deposit height of debris flows and the vulnerability of investigated elements (Papathoma et al., 2011, 2012). At first, vulnerability assessment had a purely qualitative character, but after soon people realized that only quantitative data could lead effective evaluation (Bell and Glade, 2004; Romang, 2004; Michael et al., 2003). The first curve was provided by Fuchs et al. (2007) according to the debris flow event occurred in the Wartschenbach catchment in the eastern Alps, next to the city of Lienz, Austria. Totschnig et al. (2011) adopted a modified Frechet no. 2 distribution instead of polynomial to fit the numerous data extracted from three databases. Kinematic velocity and impact pressure could also be the disaster intensity factors when the numerical simulation of debris flow was conducted (Luna et al., 2011).

So far, vulnerability curves of debris flow were mostly established based on the historic data. However, few useful data could be applied for vulnerability assessment in China since the main attention of engineering and government paid on the disasters themselves and resettlement of disaster-affected elements. Therefore, physical experiments can be an alternative method. The primary damage of building occurred during the deposit process due to the debris flow impact. $\mathrm{Hu}$ et al. (2011) monitored the impact force caused by the realscale debris flow at Jiangiia Ravine, China and exhibited the force distribution along the flow height. Bugnion et al. (2012) and Scheidl et al. (2012) analyzed the debris flow impact model based on field-scale flows and small-scale flows, respectively. They both provided the precious data for flow impact process. Canelli et al. (2012) took the material of impacted elements into account and discussed the different effects of the type of barrier on flow impact. Although some impact research of debris flow has been conducted, most of it was based on the purpose of optimizing the mitigation measure for debris flow. Therefore, they focused on the dynamics of debris flow impact rather than the response of damaged elements, and the force plate was always utilized as the substi- tute for impacted elements. Thus, it is hard to draw vulnerability curves from the prior flow-impact research. Borrowing the evaluation models of earthquake did not work well probably because the destruction mechanisms of the elements induced by these two disasters are different (HAZUS, 2006; Haugen and Kaynia, 2008).

Brick and concrete buildings are the typical civil architecture in the southwestern mountain area of China. Generally, the destruction of load-bearing walls mainly leads to the collapse of the building. Zhang (2005) studied the ultimate load-bearing capacity of brick and concrete wall in $1: 2$ scale impacted by iron spheres which were took as the substitute of debris flow. The iron spheres had the weights from 27.4 to $41.4 \mathrm{~kg}$ and the equivalent falling height was $2.9 \mathrm{~m}$ representing the potential energy that transformed to the horizontal kinetic energy. Therefore, the kinetic energy of the substitute impacting on the walls varied from 794.6 to $1200.6 \mathrm{~kg} \mathrm{~m}^{-2} \mathrm{~s}^{-2}$. There are two problems if the vulnerability curve is going to be drawn from this kind of experiment:

1. vulnerability curves contain various damage degrees of the building, while, in her research, only the destruction status was considered;

2. since the similarity law between load and geometry in structure impact experiments is unknown, the vulnerability evaluation cannot be applied in prototype.

\section{Experiment description}

\subsection{Assumption}

In this study, experiments were conducted in order to obtain the vulnerability curve for estimating the brick and concrete building with one storey. Since the collapse of building was mainly caused by the destruction of the load-bearing walls, the vulnerability assessment of the load-bearing wall of impacted building is rather representative and important.

Debris flow consists of slurry and particles. Slurry produces distributed load on elements while particles, of which the size varies in great range, produce concentrated load, and the caused damage resembles that of rock fall events (Mavrouli and Corominas, 2010). Simulating experimental or real-scale debris flow with a specific momentum is rather difficult, experimental boulders are feasible to be given certain momentum depending on their mass and falling heights or velocity. However, compared to debris flow, boulder impact produces more serious damage within the contact area because of stress concentration (e.g., a through hole). Iron board and rubber cushion were applied in Zhang's (2005) experiments to transmit the concentrated force induced by an iron sphere to distributed force which was finally exerted on the wall. According to her experiments, the wall was loaded a delta impulse which was similar to the impact loading in the field observation of the real-scale debris flow in Jiangjia 


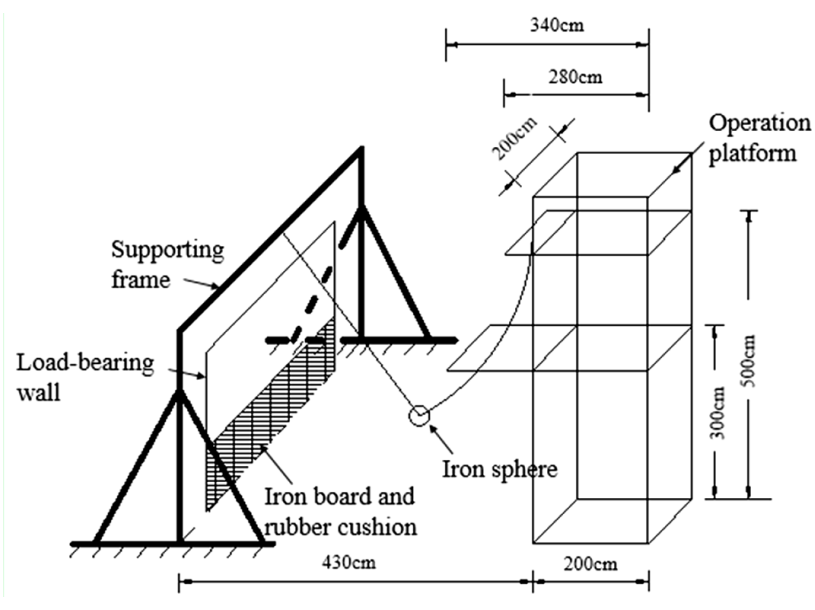

Figure 1. Experiment setup.

Ravine in China on 25 August 2004 (Hu et al., 2011): at first the impact load increased to the peak rapidly then decayed gradually in relatively long time with fluctuation. However, the impact process in field continues for more than $10 \mathrm{~s}$, and the maximum load fluctuated in approximate $5 \mathrm{~s}$ since the flow impacted the obstacle constantly for a while. In experimental conditions, the impact process associated with an iron sphere was short and had a single peak value. If taking the real-scale debris flow as a stacking process consisted of every debris flow in unit time, then there should be several peak values that represent the fluctuation of maximum load. Furthermore, if a debris flow in unit time was viewed as an overall, an iron sphere with a certain motion energy can be applied to simulate it under laboratory condition. Additionally, a delta shape signal also observed in the impact process caused by debris flow model in other research (Scheidl et al., 2012; Bugnion et al., 2012). As a result, it is assumed that the impact process induced by an experimental boulder with an iron board and a rubber cushion can represent the impact process induced by debris flows.

Generally, the impact force is $F \cdot \cos \alpha$, in which $\alpha$ is the intersection angle of the impact force and wall surface. In this study, debris flow is assumed to impact the wall vertically $\left(\alpha=90^{\circ}\right)$. Then width of the contact area of flow and elements is always equal to the width of the wall.

\subsection{Experiment setup}

Based on the assumptions mentioned above, the experiments used an iron sphere as an experimental boulder to create the concentrated load which was further distributed with an iron board and a rubber cushion. At the beginning of the experiments, the iron sphere, which was jointed to the top of supporting frame with a chain, was dragged by the dynamic system up to a certain height of operation platform. When the system power was off, the sphere would fall in a circle under gravity force and then hit the iron board in front of the wall.

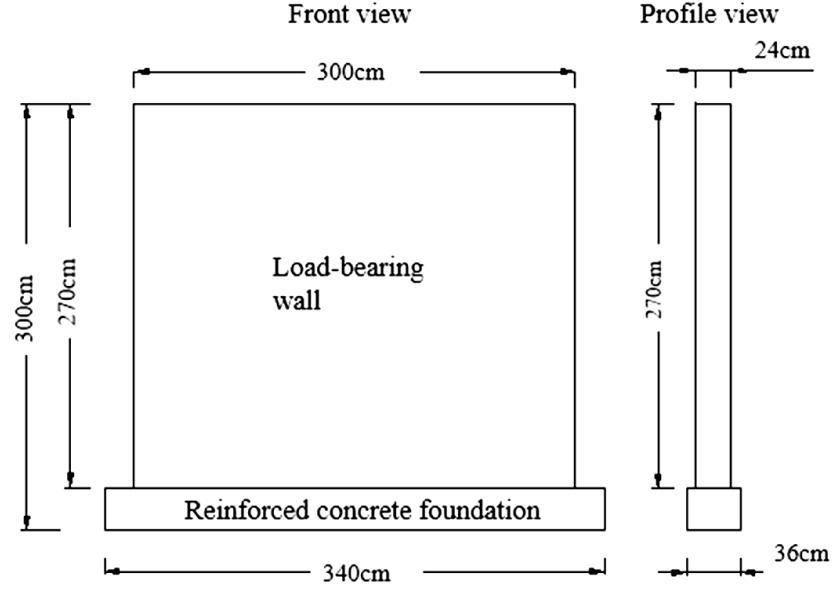

Figure 2. Sketch of load-bearing wall.

The impact point was at the geometrical center of the boards. Since the iron board was rigid, the concentrated load could spread onto the rest of the wall area covered by the board due to the displacement of the overall board. Hence, the concentrated load associated with iron sphere was transmitted to distributed load on walls. The boards represent the contact area of debris flow, and the wall since debris flow is probably wider than the wall. Therefore, the board height was the flow depth, and the board width was the average width of the contact area, which was equal to the wall width in all tests. A rubber cushion was set between the board and wall to delay the impact duration. The experiment setup is shown in Fig. 1. The operation platform (see Fig. 1) provided two falling heights $(3$ and $5 \mathrm{~m}$ ) for spheres. The support frame mounted on the ground was welded with steel. The iron sphere releasing from a certain height rotated with the circle center fixed on the beam of the frame. The debris flow in various magnitudes was simulated by releasing different spheres from different heights. In the experiments, the length of the chain and the height of the iron board were both adjustable.

The load-bearing walls in the experiments were designed and constructed according to the Chinese Brick and Concrete Structural Design Specifications (Construction Industry of China, 2011) and in alignment with the structure of the buildings mostly used in the southwestern mountain area of China. The walls were $240 \mathrm{~mm}$ thick, $3.0 \mathrm{~m}$ high and $3.0 \mathrm{~m}$ wide. The net height of the walls was $2.7 \mathrm{~m}$, and the foundation, which was $0.3 \mathrm{~m}$ deep, was made with reinforced concrete (see Fig. 2). The material of the walls was stated as follows: the brick was $240 \mathrm{~mm} \times 115 \mathrm{~mm} \times 53 \mathrm{~mm}$ and was bought from a factory. The compressive strength of the brick was $10 \mathrm{MPa}$. The mortar made of water, cement and sand was in standard curing for 28 days (temperature $=(20 \pm 2)^{\circ}$, relative humidity $\geq 90 \%$ ). The test cubes in the same curing condition for 29 days had the average compressive strength 
8.2 MPa. Make the surface of the walls as smooth as possible so that the board will attach perfectly to the wall.

\subsection{Measurement device}

An impact force gauge system including a sensor and a peak force instrument was applied to obtain the force suffered by the load-bearing wall during the impact process. At first, the sensor fixed onto the back of the wall changed the weight signal of force to electronic signal; then the electronic signal was sent to the digital display on the instrument; finally, the impact force graph during the whole process could be read and recorded by the computer. The sample frequency was $100 \mathrm{~Hz}$. Maximum dynamic and static displacement were measured with a self-made displacement gauge. The inclination of the wall $i$ is the ratio of the maximum dynamic displacement $L_{\mathrm{dd}}$ and the wall height $H$. The cracks with different widths on the wall could be identified by a crackcomparing ruler with accuracy $0.1 \mathrm{~mm}$.

\subsection{Conditions}

According to the historic debris flow events in China, the parameters of debris flow vary in a wide range (Generally, the density $\rho$ is $1.2-2.3 \mathrm{~g} \mathrm{~cm}^{-3}$; the velocity $v$ is $3-10 \mathrm{~m} \mathrm{~s}^{-1}$; the flow depth $h$ is $0-10 \mathrm{~m}$ ) (Cui et al., 2005; Tang et al., 2011b). The destructive ability of debris flows depends not only on their velocity but also volume and density. Momentum involves all these parameters and would be a good index to represent the disaster intensity of flow. The momentum of debris flow in unit time can be calculated with $m v=\rho b h v^{2}$ in which $m, \rho, b, h$ and $v$ are the mass quality, density, width and velocity of debris flow, respectively. In view of the size of lab site and the sufferance of the supporting frame, the weights of iron spheres are 49 and $86 \mathrm{~kg}$ determined by back stepping with the platform height (assuming the density of viscous debris flow $\rho$ is $2.2 \mathrm{~g} \mathrm{~cm}^{-3}$ ). The spheres are made of iron with density $7.8 \mathrm{~g} \mathrm{~cm}^{-3}$. The heights of the boards in front of the walls are $1,1.5$ and $2 \mathrm{~m}$. There are nine total experiments numbered as A1, A2, A3, B1, B2, B3, C1, C2 and $\mathrm{C} 3$. Details on the experimental programme are summarized in Table 1.

\section{Estimation method}

\subsection{Failure criterion}

Since it has been proven that the failure mode of a loadbearing wall is out-of-plane bending failure, similar to the static load condition (Zhang, 2005), cracks and inclination are important indicators of the failure of load-bearing walls impacted by debris flow. Additionally, several damage classifications of brick and concrete building from specifications of different industries (coal mining and construction) are also considered (Qian, 2013). Then, the failure criterion for the load-bearing wall impacted by debris flow is established in Table 2. However, directly applying this criterion will lead the unreasonable results when the value around the critical number is judged. For example, there is no significant different between the damaged element with maximum crack length $750 \mathrm{~mm}$ and the element with $751 \mathrm{~mm}$. However, the damage assessment of these two elements belongs to different classes according to Table 2. In this case, fuzzy mathematical theory is helpful to solve this problem.

\subsection{Estimation method based on fuzzy mathematics}

Based on fuzzy mathematics, the procedure of the vulnerability estimation of wall is stated as follows.

\subsubsection{Single index evaluation}

$U=\{a, b, c, d\}$ is the influence indicators aggregate and $a$, $b, c, d$ denote the influence indicators listed in Table 2 ,respectively. $T=\{$ I, II, III, IV $\}$ is the damage results aggregate. Then, the fuzzy relation between influence indicators and damage results can be represented with evaluation matrix $\mathbf{R}$ :

$\mathbf{R}=\left[\begin{array}{llll}r_{11} & r_{12} & r_{13} & r_{14} \\ r_{21} & r_{22} & r_{23} & r_{24} \\ r_{31} & r_{32} & r_{33} & r_{34} \\ r_{41} & r_{42} & r_{43} & r_{44}\end{array}\right]$,

in which $r_{m n}=\mu_{T_{n}}\left(U_{\mathrm{m}}\right)\left(0 \leq r_{m n} \leq 1,1 \leq m \leq 4,1 \leq n \leq 4\right)$ denotes the membership degree of the result element $T_{n}$ from the view of the indicator element $U_{m}$, and $\mathbf{R}_{m}=\left(r_{m 1}, r_{m 2}\right.$, $\left.r_{m 3}, r_{m 4}\right)$ is the assessment aggregate of $U_{m}$ and also the fuzzy subset of $T$. The membership function $\mu_{T_{n}}\left(U_{m}\right)$ has the formulas below.

$$
\begin{aligned}
& \mu_{\text {I }}\left(U_{m}\right)= \begin{cases}1, & U_{m} \leq k_{m 1} ; \\
\left(k_{m 2}-U_{m}\right) /\left(k_{m 2}-k_{m 1}\right), & k_{m 1}<U_{m} \leq k_{m 2} ; \\
0, & \text { otherwise }\end{cases} \\
& \mu_{\text {II }}\left(U_{m}\right)= \begin{cases}\left(U_{m}-k_{m 1}\right) /\left(k_{m 2}-k_{m 1}\right), & k_{m 1}<U_{m} \leq k_{m 2} ; \\
\left(k_{m 3}-U_{m}\right) /\left(k_{m 3}-k_{m 2}\right), & k_{m 2}<U_{m} \leq k_{m 3} ; \\
0, & \text { otherwise }\end{cases} \\
& \mu_{\text {III }}\left(U_{m}\right)= \begin{cases}\left(U_{m}-k_{m 2}\right) /\left(k_{m 3}-k_{m 2}\right), & k_{m 2}<U_{m} \leq k_{m 3} ; \\
\left(k_{m 3}-U_{m}\right) /\left(k_{m 3}-k_{m 2}\right), & k_{m 3}<U_{m} \leq k_{m 4} ; \\
0, & \text { otherwise }\end{cases} \\
& \mu_{\mathrm{IV}}\left(U_{m}\right)= \begin{cases}\left(U_{m}-k_{m 3}\right) /\left(k_{m 4}-k_{m 3}\right), & k_{m 3}<U_{m} \leq k_{m 4} ; \\
1, & U_{m}>k_{m 4} ; \\
0, & \text { otherwise }\end{cases}
\end{aligned}
$$

In these matrices, $\mathbf{K}_{m}=\left(k_{m 1}, k_{m 2}, k_{m 3}, k_{m 4}\right)$ denotes the membership matrix of an influence indicator and $k_{m 1}-k_{m} 4$ are the evaluation parameters of the four damage classes, respectively. The parameter adopts the mean value of the adjacent critical number. For example, the matrix of the maximum crack width $\mathbf{K}_{1}=(0.1,0.3,0.55,0.8)$. Thus, the evaluation matrix $\mathbf{R}$ can be obtained by Eqs. (2)-(5).

\subsubsection{Weight determination}

The weight determination mostly considers the over limit of indicators. Therefore, the weights of the indicators are ob- 
Table 1. Conditions of the experiments.

\begin{tabular}{lccccccccc}
\hline No. & A1 & A2 & A3 & B1 & B2 & B3 & C1 & C2 & C3 \\
\hline Height of board $(\mathrm{m})$ & 1 & 1 & 1 & 1.5 & 1.5 & 1.5 & 2 & 2 & 2 \\
Height of falling $(\mathrm{m})$ & 3 & 3 & 5 & 3 & 3 & 5 & 3 & 3 & 5 \\
Weight of sphere $(\mathrm{kg})$ & 49 & 86 & 86 & 49 & 86 & 86 & 49 & 86 & 86 \\
\hline
\end{tabular}

Table 2. Failure criterion for the load-bearing wall impacted by a single iron sphere.

\begin{tabular}{|c|c|c|c|c|c|c|}
\hline $\begin{array}{l}\text { Damage } \\
\text { class }\end{array}$ & $\begin{array}{l}\text { Maximum crack } \\
\text { width }(\mathrm{mm})\end{array}$ & $\begin{array}{l}\text { Maximum crack } \\
\text { length }(\mathrm{mm})\end{array}$ & $\begin{array}{l}\text { Total area of } \\
\text { cracks }\left(\mathrm{mm}^{2}\right)\end{array}$ & $\begin{array}{l}\text { Inclination } \\
\left(10^{3}\right)\end{array}$ & $\begin{array}{l}\text { Damage } \\
\text { description }\end{array}$ & Required repair \\
\hline I & $0-0.2$ & $0-750$ & $0-500$ & $0-1$ & slight & simple \\
\hline II & $0.2-0.4$ & $750-1500$ & $500-1000$ & $1-1.5$ & minor & minor \\
\hline III & $0.4-0.7$ & $1500-2250$ & $1000-2000$ & $1.5-2$ & mediate & mediate \\
\hline IV & $>0.7$ & $2250-3000$ & $2000-3500$ & $2-2.5$ & serious & $\begin{array}{l}\text { thorough repair } \\
\text { or rebuild }\end{array}$ \\
\hline
\end{tabular}

tained by Eq. (6) and compose the weight matrix $\mathbf{A}=\left[W_{a}\right.$, $\left.W_{b}, W_{c}, W_{d}\right]$.

$W_{U_{\mathrm{m}}}=\frac{P_{U_{\mathrm{m}}} / S_{U_{\mathrm{m}}}}{\sum_{m=1}^{4}\left(P_{U_{\mathrm{m}}} / S_{U_{\mathrm{m}}}\right)}$

In this matrix, $P_{U_{\mathrm{m}}}$ is the measured value of influence indicators; $S_{U_{\mathrm{m}}}$ is the mean value of all critical numbers. For example, the critical numbers of the maximum crack width are 0.2 , 0.4 and $0.7 \mathrm{~mm}$, then $S_{a}=(0.2+0.4+0.7) / 3=0.433 \mathrm{~mm}$.

\section{Vulnerability assessment}

Multiply the matrix $\mathbf{A}$ and $\mathbf{R}$, then generate a new matrix $\left[x_{1}\right.$, $\left.x_{2}, x_{3}, x_{4}\right]$, in which $x_{1}+x_{2}+x_{3}+x_{4}=1 . x_{1}, x_{2}, x_{3}, x_{4}$ represent the membership degrees of indicators to the damage classes (I, II, III and IV), respectively. The loss percentage $l_{n}$ for different types of damage condition is defined as below:

a. slight damage: $0-10 \%, l_{1}=10 \%$;

b. minor damage: $10-30 \%, l_{2}=30 \%$;

c. mediate damage: $30-60 \%, l_{3}=60 \%$;

d. serious damage or collapse: $60-100 \%, l_{4}=100 \%$.

As shown above, the upper limit of damage loss is defined as the loss percentage in every damage class so that the estimation will overestimate the element loss. Finally the vulnerability assessment is determined as the following:

$V=\sum_{n=1}^{4}\left(l_{n} \cdot x_{n}\right)$,

in which $V$ denotes the vulnerability of elements, namely the damage loss percentage of elements.

\section{Results and analysis}

\subsection{Damage description}

Three types of loads are discussed as follows to be the candidates of disaster intensity index for vulnerability curve.

1. Momentum - The velocity and flow depth are the basic physical descriptors of debris flow in unit width. Momentum includes both two descriptors and represents flow energy.

2. Maximum impact force - The overload of structure material is an important cause of structure failure. Therefore, maximum impact force should be taken into the consideration.

3. Maximum impact bending moment - As mentioned above, the out-of-plane bending failure was observed in previous studies as the failure mode of brick and concrete wall. The impact bending moment also contains the velocity and flow depth. Therefore, it is reasonable to consider the maximum impact bending moment as the candidate of disaster intensity index.

In order to choose the most suitable disaster intensity index from these candidates, analysis and comparison are conducted with the experimental results. The momentum, maximum impact force and maximum impact bending moment under each experimental condition are listed in Table 3.

Figures 3-5 show the cracks in series A, B and C experiments, respectively. The crack distribution is analyzed from two aspects - under the same board height and the same falling height. Directly impacted place denotes the wall area covered by board, while the rest area of the wall is indirectly impacted place. 
Table 3. Loads in experiments.

\begin{tabular}{|c|c|c|c|c|c|c|c|c|c|}
\hline Type of load & A1 & A2 & A3 & B1 & B2 & B3 & $\mathrm{C} 1$ & $\mathrm{C} 2$ & $\mathrm{C} 3$ \\
\hline Momentum $\left(\mathrm{kg} \mathrm{m}^{-1} \mathrm{~s}^{-1}\right)$ & 329 & 577.4 & 789.5 & 310.6 & 545.1 & 766.2 & 291 & 510.8 & 742.2 \\
\hline Maximum impact force $(\mathrm{kN})$ & 39 & 45 & 102.3 & 20.6 & 23.2 & 45.8 & 29.4 & 37.5 & 80.7 \\
\hline Maximum impact bending moment $\left(\mathrm{kN} \mathrm{m}^{-1}\right)$ & 18 & 22.5 & 51.15 & 15.45 & 17.4 & 34.35 & 29.4 & 37.5 & 80.7 \\
\hline
\end{tabular}

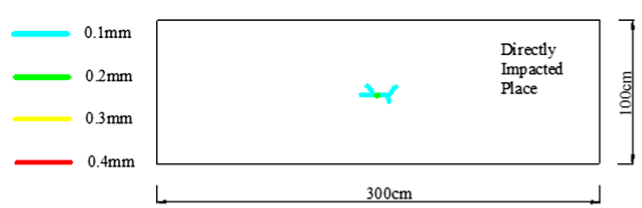

(a)

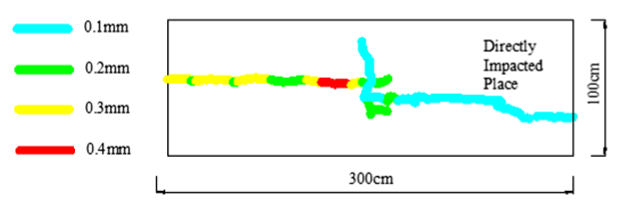

(b)

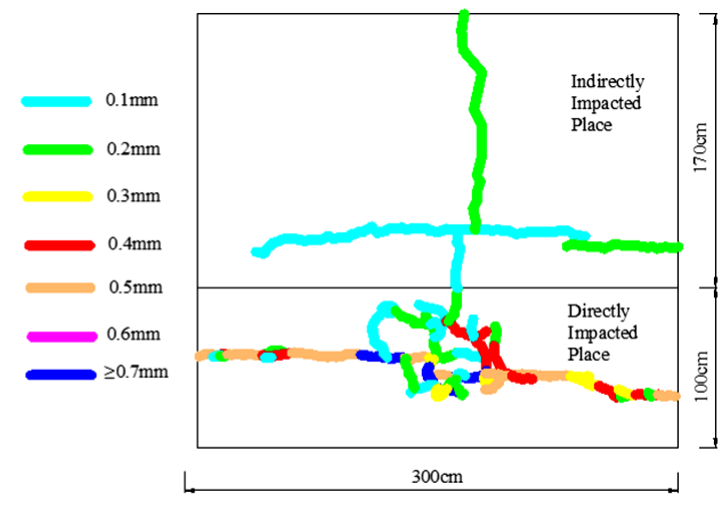

(c)

Figure 3. Distribution of the cracks on the element in series A (a, b and $\mathbf{c}$ represent the A1, A2 and A3, respectively).

\subsubsection{The same height of the iron board}

Taking the $1.0 \mathrm{~m}$ height as an example, the crack distributions of series A are shown in Fig. 3 (different motion energies or flow velocities). In A1, A2 and A3, the ratio of maximum impact force is $1: 1.15: 2.62$, the ratio of maximum bending moment is $1: 1.25: 2.84$, and the ratio of momentum is $1: 1.76: 2.4$. Under the same flow depth, the crack width, length and quantity increase when the load acting on the wall increases. In the A1 experiment, the wall still maintains completeness except for several short and tiny cracks, among which the maximum width is $0.2 \mathrm{~mm}$, and the maximum length is $273 \mathrm{~mm}$. In the A2 experiment, the cracks spread wider in horizontal direction. A part of the wall dropped the surface layer due to the deformation and tremor. Most of the cracks are $0.1-0.2 \mathrm{~mm}$ width. The maximum crack width is $0.4 \mathrm{~mm}$, and the maximum length is $2022 \mathrm{~mm}$. In the $\mathrm{A} 3$ experiment, the cracks spread onto the area above the iron broad. Both the cracks in horizontal and vertical direction extend constantly to the edge of the wall. Thus, the wall has major visible deformation in profile, and the surface layer dropped significantly from the wall. The maximum crack width is $1 \mathrm{~mm}$, and the maximum length is $3216 \mathrm{~mm}$. For the experiments with iron board heights of $1.5 \mathrm{~m}$ (B1, $\mathrm{B} 2$ and $\mathrm{B} 3)$ and $2.0 \mathrm{~m}(\mathrm{C} 1, \mathrm{C} 2$ and $\mathrm{C} 3)$ experiments, the results of the crack development in relation to impact load are similar.

\subsubsection{The same falling height}

Taking the iron sphere with a weight of $86 \mathrm{~kg}$ and falling from $3 \mathrm{~m}$ height for example (different board heights or flow depths), the crack distribution of A2, B2 and C2 experiment is shown in Figs. 3b, $4 \mathrm{~b}$ and 5b, respectively. The measured impact force in these three experiments is $45,23.2$ and $28 \mathrm{kN}$, respectively. It is found that the measured data of series B are lower than the expected value. There are at least two factors that can influence the load impacting on the wall: first, since the experiments were conducted in an outdoor lab, the weather (for example wind) can accelerate or decelerate the velocity of the iron sphere depending on their relative movement direction; second, due to the device malfunction, the tractive force between the sphere and the dynamic system did not vanish completely until the sphere departed from the system for a certain distance. This residual tractive force decreased the kinetic energy which the sphere possessed before the impact. Therefore, the spheres did not get the expected impact energies in the experiments of series B. However, the relevant damage indicators and the vulnerability also were lower than the expected value and cohered with the actual impact loads. This deviation will not influence the data analysis if only the measured data are used to establish the vulnerability curve. Table 4 includes the measured data of the indicators and the final vulnerability results based on the proposed method. From the comparison of the three figures, the total area and maximum crack length in $\mathrm{C} 2$ experiment exceed those in the A2 experiment, even though the impact force in 

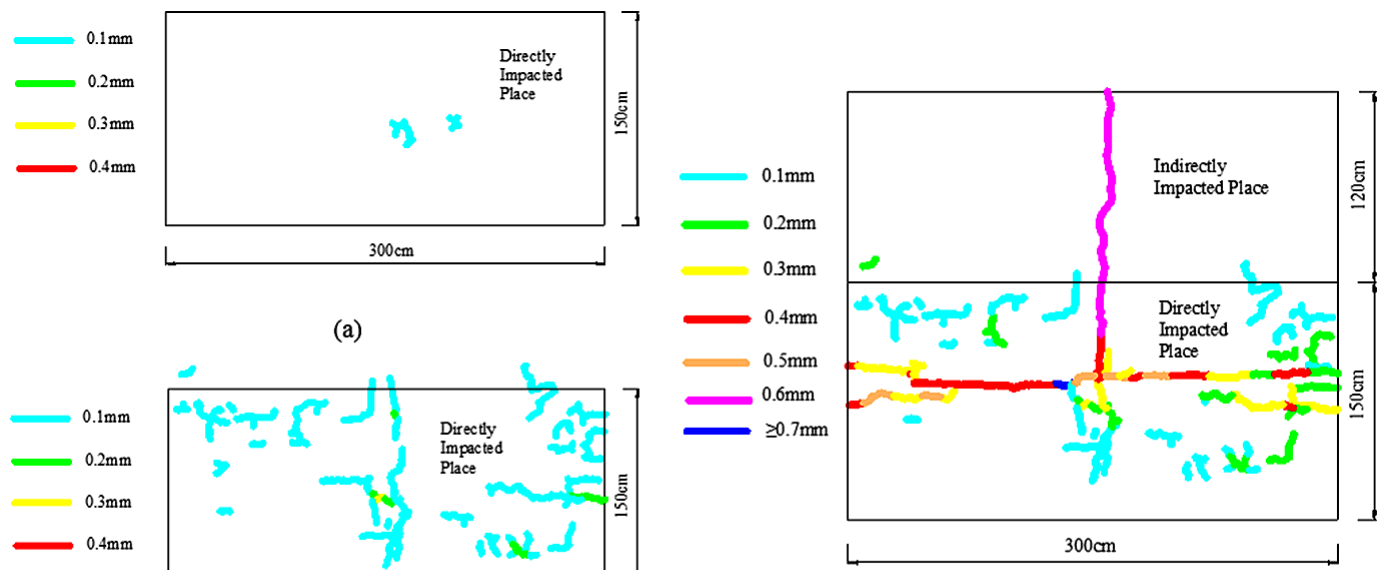

(a)

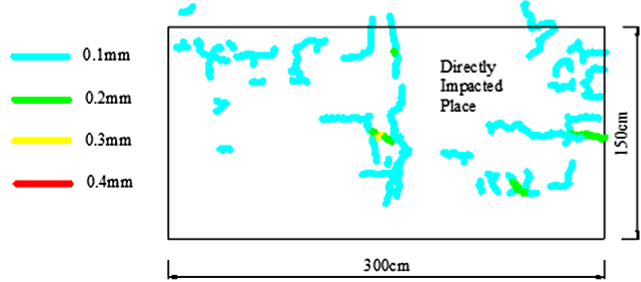

(c)

(b)

Figure 4. Distribution of the cracks on the element in series B (a, b and c represent the B1, B2 and B3, respectively).

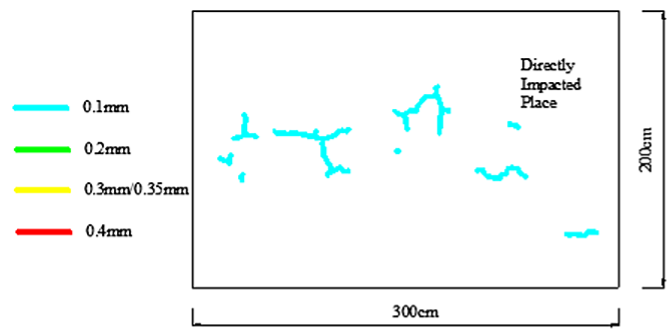

(a)
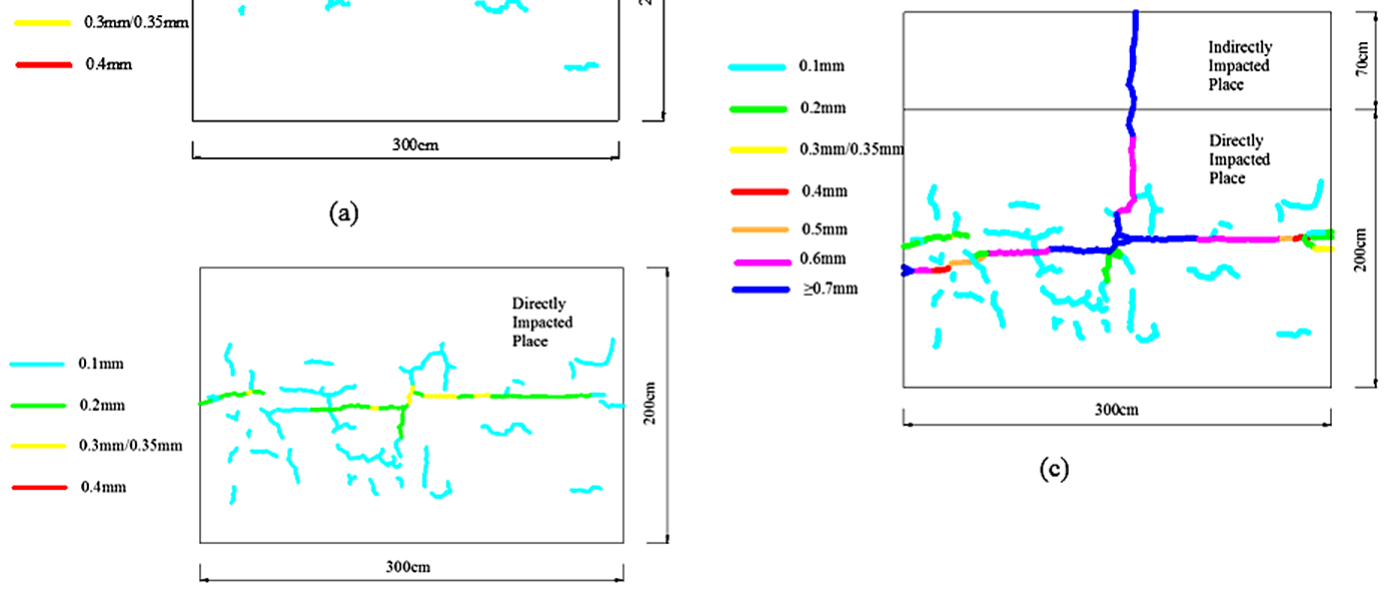

(c)

(b)

Figure 5. Distribution of the cracks on the element in series $C(\mathbf{a}, \mathbf{b}$ and $\mathbf{c}$ represent the $\mathrm{C} 1, \mathrm{C} 2$ and $\mathrm{C} 3$, respectively).

$\mathrm{A} 2$ is 1.6 times larger than that in $\mathrm{C} 2$. The vulnerability in $\mathrm{C} 2$ is 1.5 times larger than that in $\mathrm{A} 2$, and the dynamic displacement in A2 and C2 is 3.8 and $5.5 \mathrm{~mm}$, respectively. Therefore it might be deduced that the cracks are mainly caused by the dynamic displacement when the wall is swinging under the impact force.

\subsection{Vulnerability curve}

Based on the failure criterion in Table 2, the indicators of the experiments are collected in Table 4 below.
Assuming a piecewise linear function to represent vulnerability curve, therefore the curve consists of three lines. (1) At the first section of vulnerability, the value is a constant $10 \%$. (2) The vulnerability linearly varies with the disaster intensity factor when the loss percentage is between 10 and $100 \%$. (3) The vulnerability stays at $100 \%$, even if the loads increase. Arrange the vulnerability results in relation to momentum, maximum impact force and maximum bending moment, respectively, and plot them in coordinate system (see Figs. 6-8). 
Table 4. Statistical table of the influence indicators.

\begin{tabular}{|c|c|c|c|c|c|c|c|}
\hline \multirow[t]{2}{*}{ No. } & \multicolumn{3}{|c|}{ Cracks } & \multirow{2}{*}{$\begin{array}{l}\text { Inclination } \\
\qquad\left(10^{3}\right)\end{array}$} & \multirow{2}{*}{$\begin{array}{r}\text { Maximum } \\
\text { dynamic } \\
\text { displacement } \\
(\mathrm{mm})\end{array}$} & \multirow[t]{2}{*}{ Vulnerability } & \multirow[t]{2}{*}{ Crack description } \\
\hline & $\begin{array}{l}\text { Maximum } \\
\text { width } \\
(\mathrm{mm})\end{array}$ & $\begin{array}{r}\text { Maximum } \\
\text { length } \\
(\mathrm{mm})\end{array}$ & $\begin{array}{r}\text { Total } \\
\text { area } \\
\left(\mathrm{mm}^{2}\right)\end{array}$ & & & & \\
\hline A1 & 0.2 & 273 & 45.1 & 0.89 & 2.4 & $18.4 \%$ & a few and tiny \\
\hline $\mathrm{A} 2$ & 0.4 & 2022 & 611.2 & 1.41 & 3.8 & $48.2 \%$ & more and wider \\
\hline A3 & 1 & 3267 & 2944.3 & 5.00 & 13.5 & $100.0 \%$ & $\begin{array}{l}\text { constantly extend to the edge; } \\
\text { spread out of the board }\end{array}$ \\
\hline B1 & 0.1 & 204 & 48.9 & 0.78 & 2.1 & $14.0 \%$ & a few and tiny \\
\hline B2 & 0.3 & 984 & 961.2 & 1.22 & 3.3 & $31.4 \%$ & more and wider \\
\hline B3 & 0.7 & 3216 & 4196 & 1.00 & 2.7 & $90.6 \%$ & $\begin{array}{l}\text { constantly extend to the edge; } \\
\text { spread out of the board }\end{array}$ \\
\hline $\mathrm{C} 1$ & 0.1 & 591 & 303.1 & 1.22 & 3.3 & $21.0 \%$ & separated and tiny \\
\hline $\mathrm{C} 2$ & 0.3 & 2475 & 1296 & 2.04 & 5.5 & $70.9 \%$ & more and wider \\
\hline $\mathrm{C} 3$ & 1.1 & 3208 & 4192.7 & 1.96 & 5.3 & $96.8 \%$ & $\begin{array}{l}\text { constantly extend to the edge; } \\
\text { spread out of the board }\end{array}$ \\
\hline
\end{tabular}

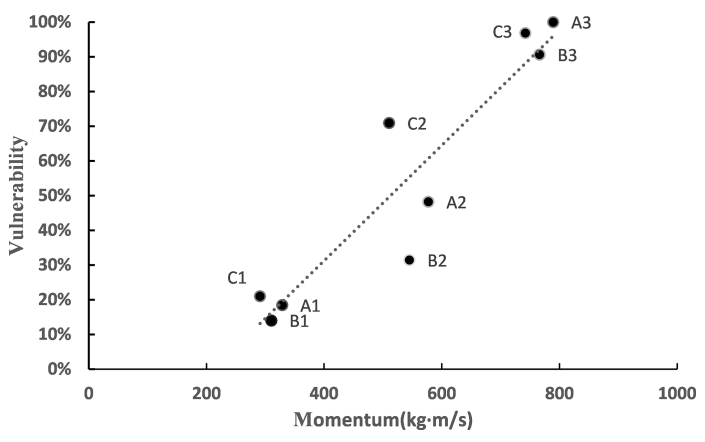

Figure 6. Vulnerability scatter chart with momentum.

\subsubsection{Momentum}

From Fig. 6, it can be found that vulnerability has a linear relation with momentum, and the data with the same momentum cluster together. However, the momentum here is just theoretical value and energy loss exists during the impact process. For example, the inelastic collision between the sphere and the board consumes the energy; the rubber cushion between the board and the wall also absorbs a part of the energy. Therefore, the actual momentum on the wall is less than the theoretical value. Unfortunately, no function can be utilized to calculate the actual momentum. As a result, the momentum in Fig. 6 is not reliable to establish the function of vulnerability.

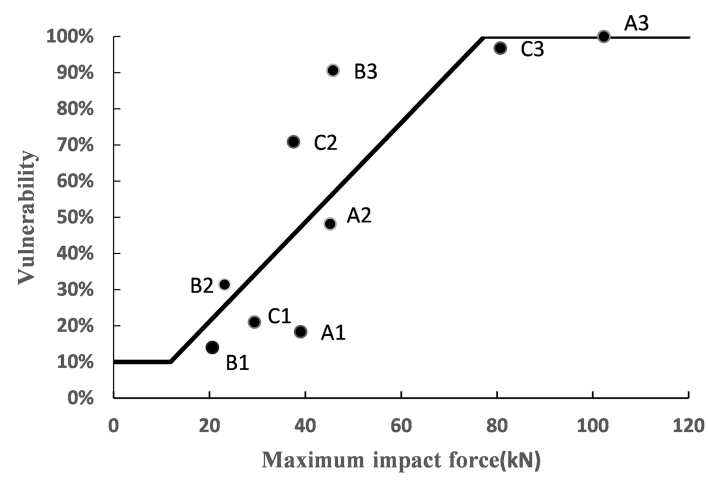

Figure 7. Vulnerability curve with maximum impact force.

\subsubsection{Maximum impact force}

The piecewise linear function with maximum impact force is written as Eq. (8) and the relation coefficient $r$ is 0.78 . The corresponding fitting curve is drawn in Fig. 7. From Fig. 7, it can be observed that the data are not closely clustered around the curve.

$$
\begin{cases}V=0.1 & F \leq 11.87 \mathrm{kN} \\ V=0.014 F-0.063 & 11.87 \mathrm{kN}<F \leq 77.34 \mathrm{kN} \\ V=1 & F>77.34 \mathrm{kN}\end{cases}
$$

\subsubsection{Maximum bending moment}

Maximum bending moment is defined as the multiplication of maximum impact force $F$ and the arm of resultant force $L=h / 2$. The piecewise linear function with maximum bend- 
ing moment is written as Eq. (9) and the corresponding fitting curve is drawn in Fig. 8. The relation coefficient is 0.87 which is higher than the coefficient with maximum impact force. From the comparison of these two figures, it can be observed that the curve with bending moment fits better with the data. If the wall is not entirely destroyed because of the impact force, the wall swings producing the dynamic displacement due to bending moment since the reinforced concrete foundation is immobile. Deformation can be partly recovered. The cracks and the static displacement are the unrecovered deformation, and the cracks are caused by the tension stress during the swing. As a result, the maximum bending moment is more likely to be the disaster intensity factor in the vulnerability estimation of brick and concrete wall.

$$
\begin{cases}V=0.1 & F \cdot L \leq 11.75 \mathrm{kNm}^{-1} \\ V=0.024(F \cdot L)-0.18 & 11.75 \mathrm{kN} \cdot m<F \cdot L \leq 49.46 \mathrm{kNm}^{-1} \\ V=1 & F \cdot L>49.46 \mathrm{kNm}^{-1}\end{cases}
$$

\section{Discussion}

The impact research of debris flow is mostly related to the characteristics of flow itself in the past. As for the elements potentially threatened by debris flow, little information can be applied to estimate or predict their vulnerability. The estimation method based on fuzzy mathematics allows the quantitatively estimation on the walls built with brick and concrete. The damage loss percentage of the walls can be calculated by collecting the indicators in Table 2 . With the derived vulnerability curve and formula, it is convenient to predict the vulnerability of the walls if the dynamic characteristics of debris flow are known. The application of the results is benefit for the insurance to be a popular kind of mitigation measure for debris flow. However, these experimental results are limited to the assumptions of experiments. Therefore, modification is necessary when the results are used for the impact event beyond the scope of assumptions. Since the quantity of the data in this study is small, the derived vulnerability curve needs more field or experimental data to promote the precision. Additionally, several problems about the experiment setup have to be clarified as below.

According to the momentum theorem $(m v=f \cdot t)$, collision duration which depends on the characteristics of material (such as elastic modulus and Poisson ratio) governs the value of impact force when the momentum remains the same. Therefore, the impact force of iron materials is 2 times larger than rock materials (or concrete materials) due to the difference of elastic modulus. In the experiments, both the experimental boulders and the boards are made of iron so the collision will create great impact force beyond the value induced by debris flow (including slurry and particles) and concrete. The composite medium consisted of rubber cushion and iron board has an elastic modulus between iron and rubber since the elastic modulus of rubber is rather small. With the increasing thickness of rubber cushion, the elastic modulus of

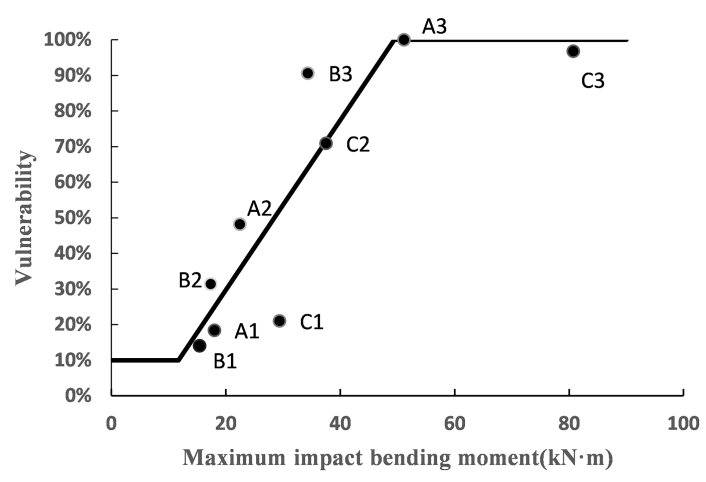

Figure 8. Vulnerability curve with maximum impact bending moment.

composite medium and the force acting on the wall decrease. Theoretically, the elastic modulus of the medium should be adjusted to cohere with historic data through preliminary experiments. Unfortunately, rare data of impact force was recorded in prototype since debris flow always occurred abruptly.

Since the rigidity of the iron board is not infinite, the board does not move as an overall. Therefore, the concentrated load cannot be transmitted to homogenous distributed load. As for the particles of debris flow, their location is random at the cross section of flow. As for the slurry of debris flow, both hydrostatic and hydrodynamic characteristics should be taken into consideration when determining the pressure application point. Thus, the load induced by debris flow is the resultant of the concentrated load with particles and the distributed load with slurry and it also deviates from homogenous distributed load. From Figs. 3-5, it seems that the cracks distributed dispersedly under most experimental conditions (A1, A2, B1, $\mathrm{B} 2, \mathrm{C} 1$ and $\mathrm{C} 2$ ) and serious damage was observed to occur around the hard contact under relatively high load. In addition, the damage degree of the wall was expressed from slight to serious under different loads. On the whole, the experiments set up can simulate the impact of debris flow properly.

The influence of transversal wall and rooftop around the load-bearing wall was not taken into consideration and both of them can provide constraint force. Since the displacement and swing are restrained, the actual loss percentage will be lower than the vulnerability evaluated based on this approach. The metal frame mounted around the wall can be applied to simulate this constraint force which should be determined by numerical or experimental test.

\section{Conclusions}

It is assumed that the impact process induced by an experimental boulder with an iron board and a rubber cushion can represent the impact process induced by debris flows since they both exert delta impulse loads on elements. The experimental results demonstrate that the maximum impact bend- 
ing moment is the principal cause of the wall damage and is more suitable to be the disaster intensity index in the vulnerability curve of the wall impacted by debris flow compared with the maximum impact force. The results also verify the conclusion of Zhang's (2005) research further, and in turn it also proves the reliability of the results. Since it takes a long time to cure the concrete, and the construction of the models is rather costly, the experimental data are limited but very precious to the vulnerability research of debris flow. The curve and formula proposed above need more field or experimental data to be more reliable. Vulnerability study is much concern on the type of the vulnerable element. The curve and formula need modification when they are applied on brick and concrete wall elements with different construction details.

Author contributions. J. Zhang, H. Qian and Z. X. Guo designed the experiments. H. Qian carried out the experiments and processed the data. J. Zhang prepared the manuscript with contributions from all co-authors.

Acknowledgements. The authors thank the support from the National Natural Science Foundation of China (No. 51409224) and the open fund program of SKLH, Sichuan University, China (No. SKHL1312). The research has also been supported by the Key Laboratory of Fluid and Power Machinery, Ministry of Education, Xihua University.

Edited by: M. Keiler

Reviewed by: B. Gems and Olga Mavrouli

\section{References}

Bell, R. and Glade, T.: Quantitative risk analysis for landslides - Examples from Bíldudalur, NW-Iceland, Nat. Hazards Earth Syst. Sci., 4, 117-131, doi:10.5194/nhess-4-117-2004, 2004.

Bugnion, L., McArdell, B., Bartelt, P., and Wendeler, C.: Measurements of hillslope debris flow impact pressure on obstacles, Landslides, 9, 179-187, doi:10.1007/s10346-011-0294-4, 2012.

Canelli, L., Ferrero, A. M., Migliazza, M., and Segalini, A.: Debris flow risk mitigation by the means of rigid and flexible barriers experimental tests and impact analysis, Nat. Hazards Earth Syst. Sci., 12, 1693-1699, doi:10.5194/nhess-12-1693-2012, 2012.

Construction Industry of China: Specification of the design of masonry structures, Beijing, 2011.

Cui, P.: Advances in debris flow prevention in China, Sci. Soil Water Conserv., 7, 7-13, 2009.

Cui, P., Chen, X., Wang, Y., Hu, K., and Li, Y.: Jiangjia Ravine debris flows in south-western China. Debris-flow Hazards and Related Phenomena, Springer Praxis Books, Springer, Berlin, Heidelberg, 565-594, 2005.

Douglas, J.: Physical vulnerability modelling in natural hazard risk assessment, Nat. Hazards Earth Syst. Sci., 7, 283-288, doi:10.5194/nhess-7-283-2007, 2007.
Fuchs, S., Heiss, K., and Hübl, J.: Towards an empirical vulnerability function for use in debris flow risk assessment, Nat. Hazards Earth Syst. Sci., 7, 495-506, doi:10.5194/nhess-7-4952007, 2007.

Haugen, E. D. and Kaynia, A .M. (Eds.): Vulnerability of structures impacted by debris flow, Taylor \& Francis Group, London, 2008.

HAZUS: Multi-hazard Loss Estimation Methodology, Earthquake Model, HAZUS MH-MR2, User Manual, FEMA and NIBS, USA, 2006.

Hu, K.,Wei, F., Li, Y.: Real-time measurement and preliminary analysis of debris flow impact force at Jiangjia Ravine, China, Earth Surf. Proc. Land., 36, 1268-1278, doi:10.1002/esp.2155, 2011.

Jakob, M., Stein, D., and Ulmi, M.: Vulnerability of buildings to debris flow impact, Nat. Hazards, 60, 241-261, doi:10.1007/s11069-011-0007-2, 2012.

Liu, K. F., Lee, H. C., and Wu, Y. H.: Assessment social impact of debris flow disaster by social vulnerability index, in: Kyoto Conference Proceeding, Kyoto, 24-31, 2012.

Liu, X. L., Mo, D. W., and Wang, X. D.: Regional vulnerability assessment of debris flows, Chinese J. Geol. Hazard Control, 12, 7-12, 2001.

Luna, Q. B., Blahut, J., Westen, J. V., Sterlacchini, S., Asch, T. W. J. V., and Akbas, S. O.: The application of numerical debris flow modelling for the generation of physical vulnerability curves, Nat. Hazards Earth Syst. Sci., 11, 2047-2060, doi:10.5194/nhess-11-2047-2011, 2011.

Mavrouli, O. and Corominas, J.: Vunerability of simple reinforced concrete buildings to damage by rockfalls, Landslides, 7, 169180, doi:10.1007/s10346-010-0200-5, 2010.

Michael, L., Baynes, F., Scott, G., and Granger, K.: Regional landslide risk to the cairns community, Nat. Hazards, 30, 233-249, 2003.

Papathoma, K. M., Kappes, M., Keiler, M., and Glade, T.: Physical vulnerability assessment for alpine hazards: state of the art and future needs, Nat. Hazards, 58, 645-680, doi:10.1007/s11069010-9632-4, 2011.

Papathoma, K. M., Keiler, M., Totschnig, R., and Glade, T.: Improvement of vulnerability curves using data from extreme events: debris flow event in South Tyrol, Nat. Hazards, 64, 20832105, 2012.

Qian, H.: Study of Vulnerability based on Debris Flows Dynamic Factors, Master Thesis, Sichuan Univ., Chengdu, 2013.

Rickenmann, D.: Empirical relationships for debris flows, Nat. Hazards, 19, 47-77, 1999.

Romang, H. (Ed.): Wirksamkeit and Kosten von WildbachSchutzmassnahmen, Verlag des Geographischen Instituts der Universität Bern, Bern, Switzerland, 2004.

Scheidl, C., Chiari, M., Kaitna, R., Müllegger, M., Krawtschuk, A., Zimmermann, T., and Proske, D.: Analysing Debris-Flow Impact Models, Based on a Small Scale Modelling Approach, Surv. Geophys., 34, 121-140, doi:10.1007/s10712-012-9199-6, 2012.

Tang, C., Zhang, J., and Zhou, C. H.: Vulnerability assessment of urban debris flow hazard, J. Catastrophol., 20, 11-17, 2005.

Tang, C., Rengers, N., van Asch, Th. W. J., Yang, Y. H., and Wang, G. F.: Triggering conditions and depositional characteristics of a disastrous debris flow event in Zhouqu city, Gansu Province, northwestern China, Nat. Hazards Earth Syst. Sci., 11, 29032912, doi:10.5194/nhess-11-2903-2011, 2011a. 
Tang, C., Zhu, J., Ding, J., Cui, X. F., Chen, L., and Zhang, J. S.: Catastrophic debris flows triggered by a 14 August 2010 rainfall at the epicenter of the Wenchuan earthquake, Landslides, 8, 485497, doi:10.1007/s10346-011-0269-5, 2011b.

Tie, Y. B.: The methodology and framework study of Urban Debris Flow Risk Assessment, PhD thesis, Chengdu University of Technology, Chengdu, 2009.

Totsching, R., Sedlacek, W., and Fuchs, S.: A quantitative vulnerability function for fluvial sediment transport, Nat. Hazards, 58, 681-703, 2011
Zhang, J., Guo, Z. X., Cao, S. Y., and Singh, V. P.: Scale model for the confluent area of debris flow and main river: a case study of the Wenjia Gully, Nat. Hazards Earth Syst. Sci., 13, 3083-3093, doi:10.5194/nhess-13-3083-2013, 2013.

Zhang, Y.: Dynamic response of mountainous civil architecture in east China impacted by debris flows, $\mathrm{PhD}$ thesis, Institute of Mountain Hazards and Environment, CAS, Chengdu, 2005. 